\title{
Intra-articular vs. systemic administration of etanercept in antigen-induced arthritis in the temporomandibular joint. Part II: mandibular growth
}

\author{
Peter Stoustrup *1, Kasper D Kristensen ${ }^{1}$, Annelise Küseler ${ }^{1}$, \\ Thomas K Pedersen ${ }^{1}$, John Gelineck ${ }^{2}$ and Troels Herlin ${ }^{3}$
}

Address: ${ }^{1}$ Department of Orthodontics, Faculty of Health Sciences, University of Aarhus, Vennelyst Boulevard 9, 8000 Aarhus C, Denmark, ${ }^{2}$ Department of Radiology, Aarhus University Hospital, Nørrebrogade 44, 8000 Aarhus C, Denmark and ${ }^{3}$ Department of Pediatrics, Aarhus University Hospital Skejby, Brendstrupgaardvej 100, 8200 Aarhus N, Denmark

Email: Peter Stoustrup* - pstoustrup@odont.au.dk; Kasper D Kristensen - kdahl@odont.au.dk; Annelise Küseler - annelise@boye.dk; Thomas K Pedersen - tklit@odont.au.dk; John Gelineck - jgeli@as.aaa.dk; Troels Herlin - troeherl@rm.dk

* Corresponding author

Published: 6 February 2009

Pediatric Rheumatology 2009, 7:6 doi:10.1186/1546-0096-7-6
Received: 8 September 2008

Accepted: 6 February 2009

This article is available from: http://www.ped-rheum.com/content/7///6

(c) 2009 Stoustrup et al; licensee BioMed Central Ltd.

This is an Open Access article distributed under the terms of the Creative Commons Attribution License (http://creativecommons.org/licenses/by/2.0), which permits unrestricted use, distribution, and reproduction in any medium, provided the original work is properly cited.

\begin{abstract}
Background: Temporomandibular joint (TMJ) arthritis in children causes alterations in the craniomandibular growth. Resultant abnormalities include; condylar erosions, a posterior mandibular rotation pattern, micrognathia, malocclusion with an anterior open bite, altered joint and muscular function occasionally associated with pain. These alterations may be prevented by early aggressive anti-inflammatory intervention. Previously, we have shown that intra-articular (IA) corticosteroid reduces TMJ inflammation but causes additional mandibular growth inhibition in young rabbits. Local blockage of TNF- $\alpha$ may be an alternative treatment approach against TMJ involvement in juvenile idiopathic arthritis (IIA). We evaluated the anti-inflammatory effect of IA etanercept compared to subcutaneous etanercept in antigen-induced TMJ-arthritis in young rabbits in terms of mandibular growth. This article (Part II) presents the data and discussion on the effects on facial growth. In Part I the anti-inflammatory effects of systemic and IA etanercept administration are discussed.
\end{abstract}

Methods: Arthritis was induced and maintained in the TMJs of 10 -week old pre-sensitized rabbits $(n=42)$ by four repeated IA TMJ injections with ovalbumin, over a 12-week period. One group was treated weekly with systemic etanercept $(0.8 \mathrm{mg} / \mathrm{kg})(\mathrm{n}=14)$, another group $(n=14)$ received IA etanercept $(0.1 \mathrm{mg} / \mathrm{kg})$ bilaterally one week after induction of arthritis and one group $(n=14)$ served as an untreated arthritis group receiving IA TMJ saline injections. Head computerized tomographic scans were done before arthritis was induced and at the end of the study. Three small tantalum implants were inserted into the mandible, serving as stable landmarks for the super-impositions. Nineteen variables were evaluated in a mandibular growth analysis for inter-group differences. All data was evaluated blindedly. ANOVA and T-tests were applied for statistical evaluation using $P<0.05$ as significance level.

Results: Significant larger mandibular growth disturbances were observed in the group receiving IA saline injections compared with the systemic etanercept group. The most pronounced unfavourable posterior mandibular rotation pattern was observed in the group receiving IA saline injections.

Conclusion: Intervention with systemic etanercept monotherapy equivalent to the recommended human dose allows a mandibular growth towards an original morphology in experimental TMJ arthritis. Systemic administrations of etanercept are superior to IA TMJ administration of etanercept in maintaining mandibular vertical growth. 


\section{Background}

Temporomandibular joint (TMJ) arthritis in growing individuals severely affects the endochondral ossification in the condylar cartilage responsible for a substantial part of the mandibular growth $[1,2]$. The intracapsular location of this growth cartilage is a unique characteristic of the TMJ and it makes this joint vulnerable to inflammatory changes. It is evident that the pronounced mandibular growth deviations seen in juvenile idiopathic arthritis (JIA) patients is a consequence of TMJ arthritis [3-5]. Resultant abnormalities include; condylar deformities, reduced vertical mandibular ramus growth, a critical posterior clockwise mandibular rotation pattern and reduced muscular and TMJ function, occasionally associated with pain, and a secondary affection of the maxilla and soft tissue [3-6]. JIA patients with TMJ involvements are mainly treated with orthopaedic procedures and corrective surgery after mandibular growth disturbances have occurred $[7,8]$. These treatment modalities are long of duration, comprehensive and require excellent patient cooperation. We hypothesize that early aggressive intervention against TMJ arthritis aimed against the inflammatory process per $s e$ would be advantageous and allow mandibular growth towards an original morphology. Beneficial symptomatic and functional improvements of intra-articular (IA) corticosteroid injections for the treatment of TMJ arthritis in children with JIA have been described [9-11]. However, these studies do not address the potential negative longterm effects of IA TMJ corticosteroid injections on condylar cartilage and craniofacial growth. This calls for attention since long-term side-effects on mandibular growth may outweigh the beneficial short-term effects. Previously, we have published data to support that, despite of significant inflammatory reduction, IA TMJ corticosteroid injections seem to have unfavourable effects on the mandibular growth in experimental studies $[12,13]$. As always, it requires caution and careful consideration when applying the findings in an experimental TMJ arthritis model to humans but our previous findings warrant the search for alternative local anti-inflammatory treatment procedures.

TNF- $\alpha$ plays an important role in the pathogenesis of JIA, and high levels of TNF- $\alpha$ are associated with a negative effect on the endochondral ossification [14-17]. Additionally, in rheumatoid arthritis (RA) TMJ pain and tissue destruction are associated with elevated synovial levels of TNF- $\alpha[18,19]$. In polyarticular JIA not responding to standard DMARD therapy with methotrexate, the efficacy and safety of etanercept given subcutaneously have been well documented [20]. In RA patients IA etanercept has shown a good response in terms of symptomatic relief $[21,22]$. No previous study has addressed the topic of mandibular growth and anti-TNF- $\alpha$ therapy against TMJ arthritis.
In the present study we investigated the effect of systemic and IA administration of etanercept on mandibular growth in experimental antigen-induced TMJ arthritis in rabbits. We hypothesized that the anti-inflammatory treatment with TNF- $\alpha$ blockers would allow a mandibular growth towards an original morphology in antigeninduced TMJ arthritis compared to an IA saline treated group. The anti-inflammatory effects of the etanercept interventions are described in part I: Histological Effects [23].

\section{Methods}

Ten-week old female New Zealand white rabbits $(\mathrm{n}=42)$ (Oryctolagus cuniculus) were housed at the animal facilities of the University of Aarhus, Denmark, with free access to water and food. Animal welfare was monitored by daily evaluation of food and water intake. Prior to arrival the animals were randomly divided into three groups by block randomisation; a) IA TMJ saline group, $\mathrm{n}=14(0.1$ $\mathrm{ml}$ pr. joint), b) IA TMJ etanercept group, $\mathrm{n}=14(0.1 \mathrm{mg} /$ kg pr. joint), c) systemic etanercept group, $\mathrm{n}=14(0.8 \mathrm{mg} /$ kg subcutanously). All animals had TMJ arthritis induced as described in Part I [23] (figure 1).

Prior to T1 all animals had three $1.0 \times 0.33 \mathrm{~mm}$ tantalum implants inserted in the mandible serving as stable landmarks used in the mandibular growth analysis [1,24]. One implant was inserted close to the mandibular symphysis and another in the molar region in both sides of the mandible. Two sets of full head CT scans (Phillips/ Mx8000 IDT 16) were taken at T1 and at T2 (age 26 weeks); resulting in a growth period of 12 weeks. All animals were sacrificed at age 26 weeks. Implant operation, TMJ injections and euthanization were carried out under general anaesthesia and all procedures were approved by the Danish Ethical Committee for animal welfare. IA injections and surgical procedures were carried out in a blinded fashion by trained specialists.

\section{Growth variables}

Evaluation of inter-group growth differences between T1 and T2 were evaluated by a mandibular growth analysis based on CT scans. Figure 2 shows the anatomical landmarks and implants used for definition of the variables evaluated. Figures 3, 4 and 5 show the 19 variables evaluated at $\mathrm{T} 1$ and $\mathrm{T} 2$ used in the analysis of mandibular morphology changes in each animal. Variables describing vertical and sagittal changes were obtained from the right side of the animals.

The scanned images were digitised by one author (PS) using the image evaluation software program Mimics (Mimics 11, Materialise, Leuven, Belgium) and all images were assessed in a blinded fashion before group assignment was revealed. Only statistical analyses prespecified 


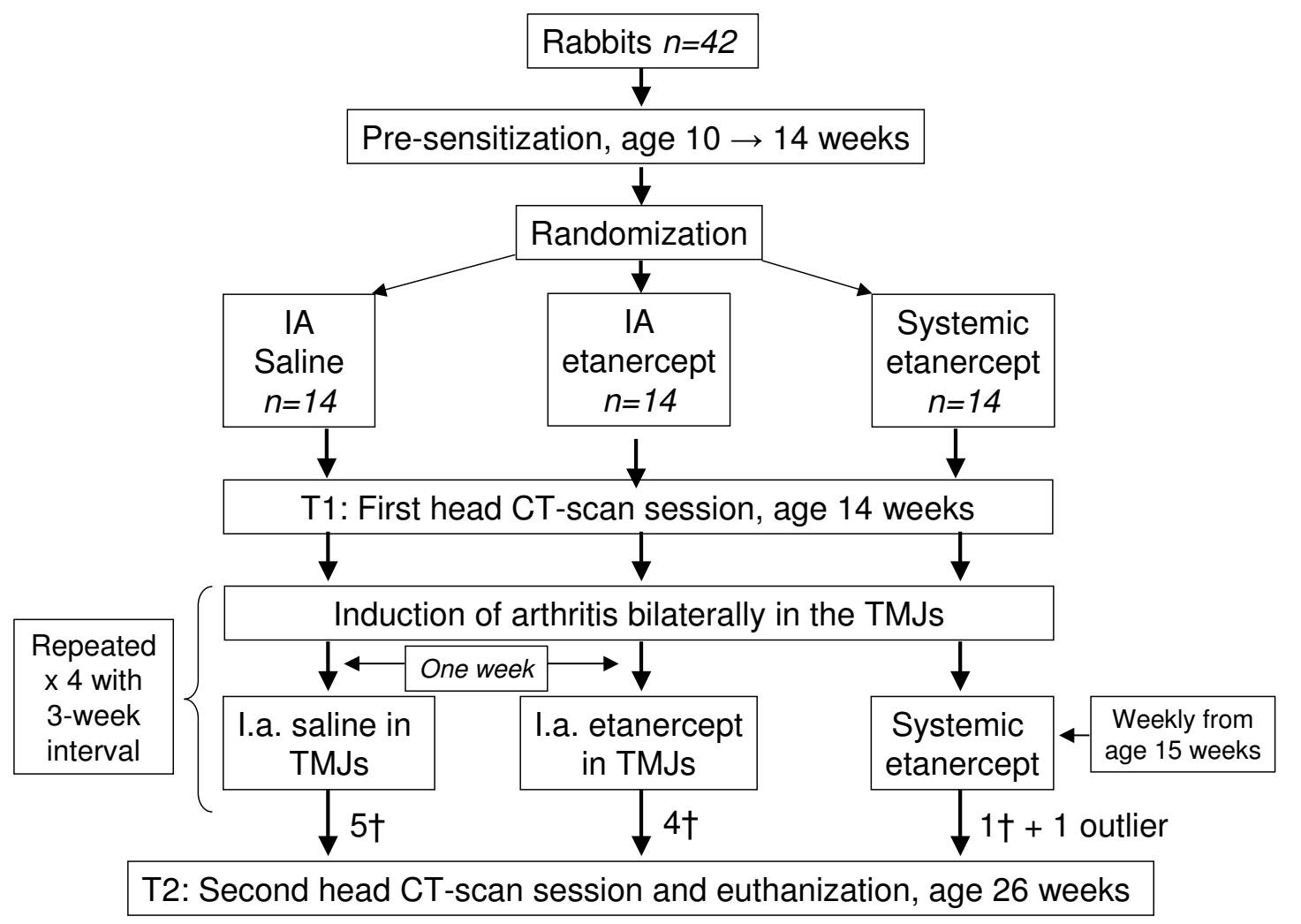

Figure I

Flow chart illustrating the study design.

in the investigation protocol were performed. The data were statistically processed using the software program Stata (Intercooled Stata 8.2, StataCorp, Texas, USA).

\section{Statistics}

All continuing variables were evaluated for normal distribution. At T1, absolute inter-group differences for each of the nineteen variables were evaluated by one-way ANOVA-tests. Sagittal, vertical and transverse intra-group growth between $\mathrm{T} 1$ and $\mathrm{T} 2$ were evaluated by paired ttests. In each of the nineteen variables differences in the relative inter-group growth between $\mathrm{T} 1$ and $\mathrm{T} 2$ were evaluated using one-way ANOVA-tests. Student's t-tests were applied as post-ANOVA tests in variables when significance was found in the ANOVA-tests. The necessity for a Bonferroni correction for avoidance of mass significance in the post-ANOVA inter-group Student's t-tests was discussed. However, to avoid type-2 errors due to the correlation between the nineteen variables evaluated in each animal, this correction was found too strong and not implemented in the statistical analysis. In a previous study, acceptable intra-observer variance and inter-scan accuracy were demonstrated using the same measuring methods, equipment and observer as in this study [13]. Power calculations were performed at $\mathrm{T} 2$ in order to eval- uate the validity of our findings in relation to the number of animals completing the study. The parameters for the calculations were $2 \alpha=0.05$ and $\beta=20$. Discussed below are only findings sufficiently powered. The level of significance used was $\mathrm{p}<0.05$.

\section{Results}

Thirty-two animals completed the study. The distribution of the completers at T2 were; nine from the IA saline group, ten from the IA etanercept group and thirteen from the systemic etanercept group. One animal from the systemic etanercept group was excluded from the final growth analysis due to abnormal histological TMJ findings in this animal [23].

At T1 mandibular maturation was identical for all three study groups. This was confirmed by no absolute intergroup differences in any of the nineteen cephalometric variables at T1 (Table 1). Significant sagittal, vertical and transverse intra-group growth in almost all of the three groups was observed during the 12 weeks of growth $(\mathrm{p}<$ $0.05)$. An exception for this was the growth of the dentoalveolar height (DAH) in the IA etanercept group which did not demonstrate growth between $\mathrm{T} 1$ and $\mathrm{T} 2$. This is explained by the small growth increment and the large 


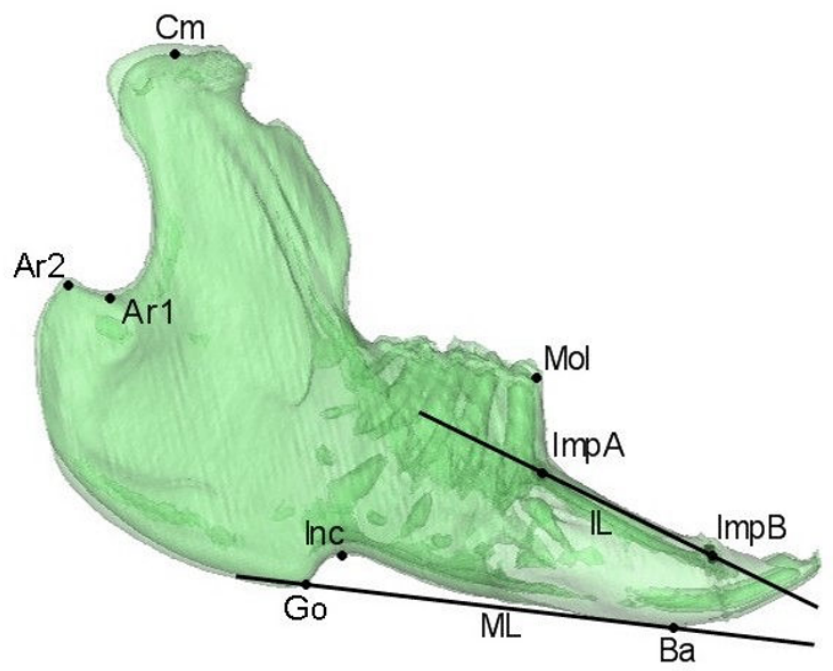

Figure 2

Anatomical landmarks. Cm (Condylar midpoint), ArI (Articulare I), Ar2 (Articulare 2), Go (Gonion), Ba (Basion point), Inc (Incisal point), Mol (Molar point). The implant points were located on the right side: ImpA (Implant A) and ImpB (Implant B). The following two lines were defined: $\mathbf{M L}$ (Mandibular line) from $\mathrm{Go}$ to $\mathrm{Ba}$, defined at the right side; IL (Implant line) going through ImpA-ImpB. For specific definitions of the anatomical landmarks see Stoustrup et al. 2008 [12].

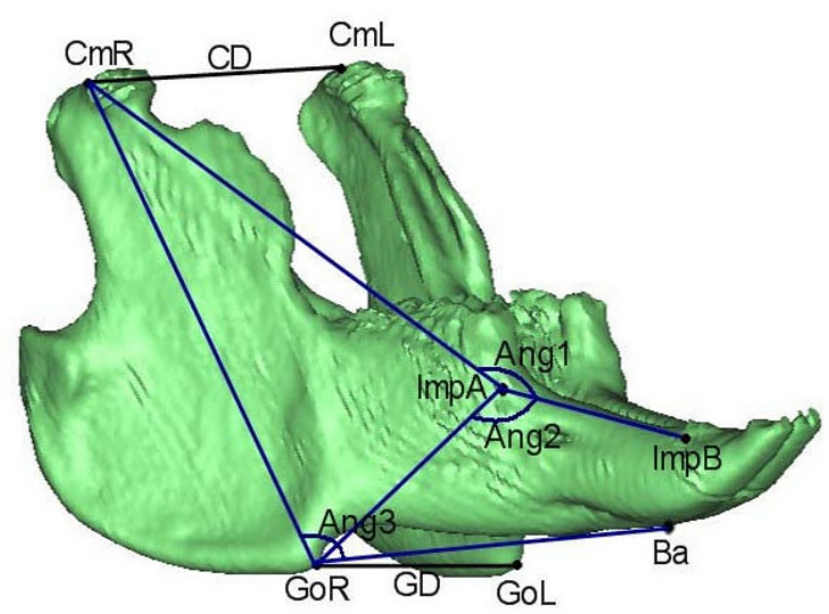

\section{Figure 3}

Angles and transverse variables measured. Angle I: Cm-ImpA-ImpB; Angle2: Go-ImpA-ImpB; Angle3: Cm-Go$\mathrm{Ba}$; Condylar distance (CD): $\mathrm{Cm}_{\text {right }}-\mathrm{Cm}_{\text {left }}$; Gonial distance (GD): $\mathrm{Go}_{\text {right }}-\mathrm{Go}_{\text {left }}$.

variation in the growth of this variable. The implant A to implant B distances did not change between T1 and T2. This documents the stable properties of the implants inserted. Between T1 and T2 angle 1 did not open signifi-

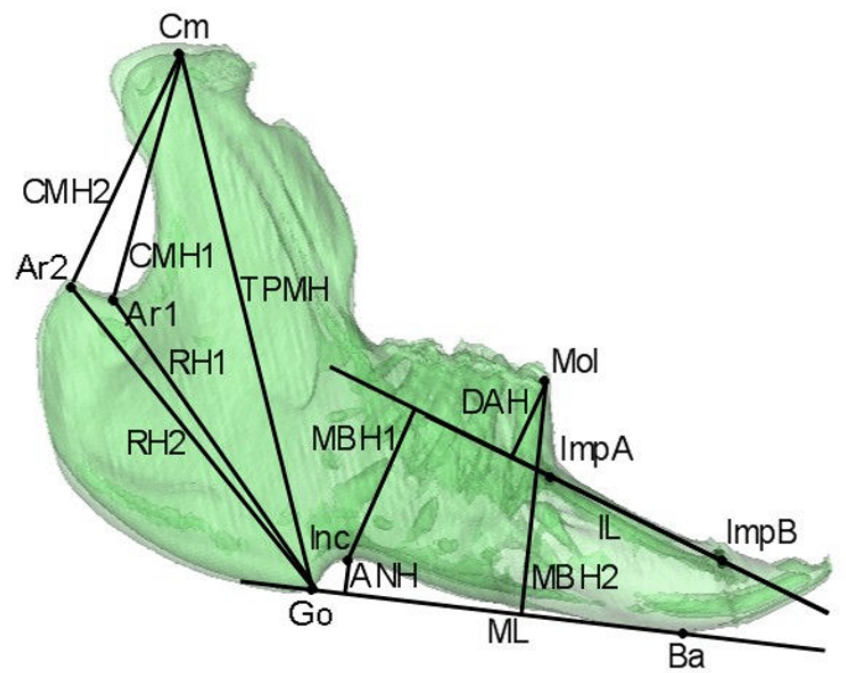

Figure 4

Vertical variables measured. Total posterior mandible height (TPMH): Cm-Go; Collum mandibular height I (CMHI): Cm-Arl; Collum mandibular height 2 (CMH2): Cm-Ar2; Ramus height I (RHI): Arl-Go; Ramus height 2 (RH2): Ar2-Go; Mandibular body height I (MBHI) Inc $\perp$ IL; Mandibular body height 2 (MBH2): Mol $\perp$ ML; Dentoalveolar height (DAH): Mol $\perp$ IL; Height of angular notch $(\mathrm{ANH})$ : Inc $\perp \mathrm{ML}$.

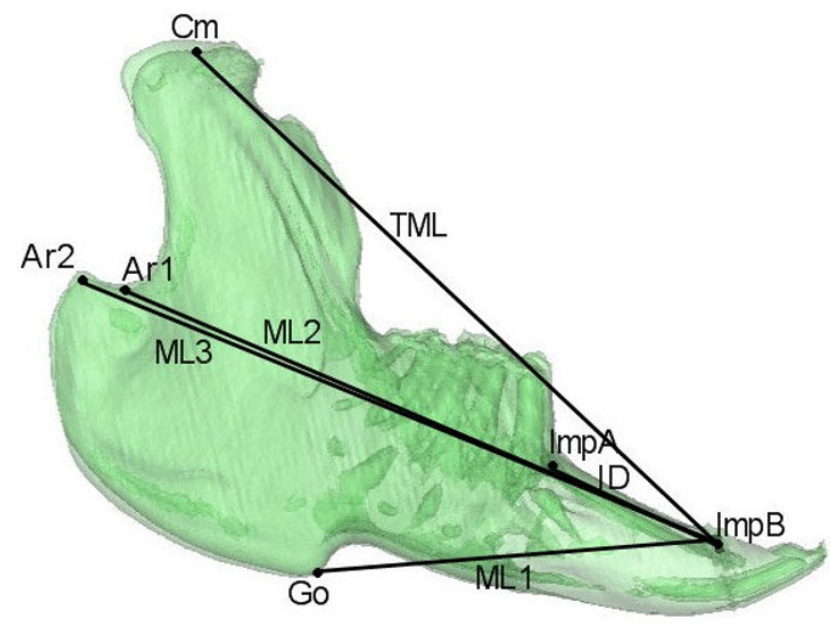

Figure 5

Sagittal variables measured. Mandibular length I (MLI) Go-ImpB; Mandibular length 2 (ML2) ArI-ImpB; Mandibular length 3 (ML3) Ar2-ImpB; Total mandibular length (TML) Cm-ImpB; Implant distance (ID): ImpAImpB. Figures from Stoustrup et al. 2008 [12].

cantly in any of the groups; Angle 2 closed significantly only in the IA saline group and Angle 3, signifying the angle between the ramus and the horizontal plane of the mandible, opened significantly in all three groups. 
Evaluation of relative inter-group differences in mandibular growth during the 12 weeks of growth observed we found no significant differences in terms of angular, sagittal and transverse mandibular maturation and growth. In the vertical dimension a significant relative inter-group difference in mandibular growth was observed in the total posterior mandibular height (TPMH) $(\mathrm{p}<0.05)$. PostANOVA tests showed that the relative growth of the total posterior mandibular height (TPMH) was significantly larger in the systemic etanercept group $(\mathrm{p}<0.05)$, but not for the IA etanercept group, compared with the IA saline group of animals (figure 6). A non-significant trend ( $\mathrm{p}<$ 0.1 ) towards a difference in the relative growth of the TPMH was observed between the systemic etanercept group and the IA etanercept group. In variables such as the mandibular body height 1 (MBH1) and the antegonial notching height (ANH) large inter-group differences in the relative growth were observed but due to the combination of large variations and a small growth in these variables no significant differences were observed.

\section{Discussion}

In this study we have demonstrated that subcutaneous etanercept administration, in a weekly dose of $0.8 \mathrm{mg} / \mathrm{kg}$, allows a mandibular growth towards an original morphology. Additionally, we found that systemic etanercept is superior to IA etanercept administration $(0.1 \mathrm{mg} / \mathrm{kg}$ at times of inflammatory flares) in supporting mandibular vertical growth. In terms of mandibular rotational growth, all three experimental groups demonstrated an unfavourable posterior clockwise mandibular rotation pattern illustrated by an opening of the mandibular angle (Angle 3) (figure 7). However, most critical posterior rotation pattern was observed in the IA saline group in which a closing of Angle 2 occurred additionally. Reduced vertical mandibular growth and mandibular posterior rotation are two of the most pronounced and critical clinical features in JIA patients with inflammatory TMJ changes $[3,5]$. Both of these features are signs of very unfavourable mandibular growth $[1,24]$.

The findings in this study indicate that the mandibular growth is most efficiently supported by a weekly systemic anti-inflammatory and immunomodulatory therapy compared to a local anti-inflammatory therapy at times of inflammatory flares. However, there are several possible reasons for the lack of effect of IA etanercept in this study that need further attention. It is not known how long IA administered etanercept stays in the joint before being absorbed and entering circulation: etanercept has an elimination half life between 70.8 and 96.4 hours [25]. Despite of an expected higher concentration of TNF- $\alpha$ inhibitor within the TMJs, achieved by IA injections compared to systemic etanercept administration, the duration of IA injected etanercept seems to have an insufficient clinical effect on the TMJ arthritis to result in beneficial long-term results on mandibular growth. The concentration of the IA etanercept injected could therefore have been insufficient. The dose of the systemically administered etanercept $(0.8 \mathrm{mg} / \mathrm{kg}$ subcutaneously) used in this study is in agreement with the recommended weekly dose of etanercept in humans [20]. This dose is not equivalent to the dose of IA etanercept administered and this may explane our findings. At the beginning of this study the IA etanercept concentration used $(0.1 \mathrm{mg} / \mathrm{kg})$ was decided based on the sparse information published on IA etanercept in letters and case reports. After initiating our study, Bliddal et al. described good symptomatic and functional results by the use of IA etanercept injections in RA patients (wrist, knee or elbow) with injections of $0.3 \mathrm{mg} / \mathrm{kg}$ etanercept (25 mg/joint) [22].

Aspects to consider in future studies are whether to give IA injections more frequently than at times of flares, increase the IA injected etanercept concentration, use another TNF$\alpha$ inhibitor with a prolonged elimination, or to see if the effect of IA etanercept injections would have been improved when supported by another anti-inflammatory or immunomodulatory systemically administered therapy. Recently, repeated IA infliximab (Remicade ${ }^{\varpi}$, Centocor) injections in the TMJ in RA patients have been described with good results [26].

In the present study, the IA saline group and IA etanercept group animals received more TMJ injections per animal than the systemic etanercept group animals. Histologically, we have shown that IA TMJ saline injections per se do not result in any inflammatory or destructive changes in the joint [12]. Therefore, the fact that the number of TMJ injections per joint per se being lower in the systemic etanercept group does not seem to be of crucial importance for the influence on mandibular growth.

It requires special caution and careful consideration when applying findings in experimental studies to humans. In this study we used etanercept (a humanized TNF- $\alpha$ receptor fusion protein) for the treatment of inflammation in rabbits. However, etanercept has a documented effect on rabbit inflammation as described in Part I of this study [23]. Additionally, non-pathological rabbit mandibular growth resembles non-pathological human mandibular growth [27]. The experimental arthritis model used in this study is well described [28]. It shows similar mandibular growth deviations in rabbits compared to the pathologically mandibular growth deviations seen in JIA children with inflammatory TMJ changes [29].

In rabbits approximately $90 \%$ of the overall mandibular growth is achieved before the sixteenth week and has almost ceased at age 26 weeks [30]. Yet, launching this 
Table I: Absolute intra-group differences between TI (week 14) and T2 (week 26) together with mean relative difference for each of the variables in each group evaluated.

\begin{tabular}{|c|c|c|c|c|c|c|c|}
\hline Variable & Group & $\begin{array}{c}\text { Absolute mean } \\
\text { TI value }\end{array}$ & $\begin{array}{c}\text { Absolute mean } \\
\text { T2 value }\end{array}$ & $\begin{array}{l}\text { Absolute mean } \\
\text { difference T2-TI }\end{array}$ & $\begin{array}{c}\text { Relative mean } \\
\text { difference from TI } \\
\text { to T2 }(\%)\end{array}$ & $\begin{array}{c}\text { Standard } \\
\text { deviation (\%) }\end{array}$ & $\begin{array}{c}\text { Statistical significance } \\
\text { for growth between } \\
\text { TI and } \mathrm{T} 2\end{array}$ \\
\hline \multirow[t]{3}{*}{ Angle I } & A & 155.3 & 156.6 & 1.3 & 0.84 & 1.7 & n.s. \\
\hline & B & 155.8 & 156.4 & 0.6 & 0.4 & 2.9 & n.s. \\
\hline & C & 153.9 & I54.I & 0.2 & 0.1 & 1.6 & n.s. \\
\hline \multirow[t]{3}{*}{ Angle 2} & A & 136.1 & 133.8 & -2.3 & -1.7 & 2.2 & $*$ \\
\hline & B & 136.2 & 135.1 & -1.1 & -0.7 & 5.2 & n.s. \\
\hline & C & 138.7 & 137.4 & -1.3 & -1 & 2.2 & n.s. \\
\hline \multirow[t]{3}{*}{ Angle 3} & $A$ & 108.3 & 109.3 & 1 & 0.9 & 1.2 & $*$ \\
\hline & B & 107.3 & 108.6 & 1.3 & 1.3 & 1.5 & $*$ \\
\hline & C & 108.3 & 109.6 & 1.3 & 1.2 & 1.3 & $*$ \\
\hline \multicolumn{8}{|l|}{ Sagittal $(\mathrm{mm})$} \\
\hline TML & A & 61.5 & 66.6 & 5.1 & 8.3 & 2.1 & $*$ \\
\hline \multirow[t]{2}{*}{$(\mathrm{Cm}-\mathrm{ImpB})$} & B & 60.7 & 65.8 & 5.1 & 8.4 & 1.9 & $*$ \\
\hline & C & 60.8 & 66.2 & 5.4 & 8.8 & 1.8 & $*$ \\
\hline MLI & A & 36.2 & 38.1 & 1.9 & 5 & 2.4 & $*$ \\
\hline \multirow[t]{2}{*}{ (Go-ImpB) } & B & 36.5 & 38.2 & 1.7 & 4.6 & 2.5 & $*$ \\
\hline & C & 35.9 & 37.6 & 2 & 5 & 2.1 & $*$ \\
\hline ML2 & A & 55.6 & 59.7 & 4.1 & 7.3 & 1.7 & $*$ \\
\hline \multirow[t]{2}{*}{$(A r I-I m p B)$} & B & 55.3 & 59.0 & 3.7 & 7.2 & 2.2 & $*$ \\
\hline & C & 54.8 & 58.7 & 3.9 & 7.2 & 2.6 & $*$ \\
\hline ML3 & A & 58.6 & 63.3 & 4.7 & 8 & 1.8 & $*$ \\
\hline \multirow[t]{2}{*}{ (Ar2-ImpB) } & B & 58.6 & 63.1 & 4.5 & 7.7 & 0.9 & $*$ \\
\hline & C & 58.3 & 62.8 & 4.5 & 7.7 & 1.4 & $*$ \\
\hline ID & A & 15.1 & 15.5 & 0.4 & 3 & 6.2 & n.s. \\
\hline \multirow[t]{2}{*}{ (impA-impB) } & B & 14.8 & 15.1 & 0.3 & 2.7 & 5.8 & n.s. \\
\hline & C & 14.1 & 14.0 & -0.1 & -1.3 & 8.1 & n.s. \\
\hline
\end{tabular}

Vertical (mm)

\begin{tabular}{|c|c|c|c|c|c|c|c|}
\hline TPMH & A & 44.2 & 48.8 & 4.6 & 10.4 & 1.5 & $*$ \\
\hline \multirow[t]{2}{*}{$(C m R-G o R)$} & B & 43.3 & 47.9 & 4.6 & 10.8 & 1.9 & $*$ \\
\hline & C & 43.5 & 49.0 & 5.5 & 12.6 & 1.7 & $*$ \\
\hline $\mathrm{CMHI}$ & A & 21.4 & 23.7 & 2.3 & 10.7 & 1.1 & $*$ \\
\hline \multirow[t]{2}{*}{ (CmR-Arl) } & B & 21.1 & 23.2 & 2.1 & 9.9 & 3.5 & $*$ \\
\hline & C & 21.3 & 23.6 & 2.3 & 10.8 & 2.6 & $*$ \\
\hline $\mathrm{CMH} 2$ & A & 22.3 & 24.3 & 2 & 8.9 & 2.0 & $*$ \\
\hline \multirow[t]{2}{*}{$(C m R-A r 2)$} & B & 22.2 & 24.3 & 2.1 & 9.4 & 2.9 & $*$ \\
\hline & C & 22.1 & 24.4 & 3.3 & 10.0 & 2.3 & $*$ \\
\hline $\mathrm{RHI}$ & A & 27.4 & 30.3 & 2.9 & 10.7 & 2.5 & $*$ \\
\hline \multirow[t]{2}{*}{$(A r l-G o R)$} & B & 26.8 & 29.7 & 2.9 & 11.0 & 2.3 & $*$ \\
\hline & C & 26.8 & 29.9 & 3.1 & 11.6 & 3.5 & $*$ \\
\hline $\mathrm{RH} 2$ & A & 29.5 & 32.9 & 3.4 & 11.9 & 3.4 & $*$ \\
\hline \multirow[t]{2}{*}{$(A r 2-G o R)$} & B & 28.9 & 32.5 & 3.6 & 12.3 & 2.5 & $*$ \\
\hline & C & 29.2 & 32.9 & 3.7 & 12.7 & 2.7 & $*$ \\
\hline $\mathrm{MBHI}$ & A & 12.5 & 13.8 & 1.3 & 10.4 & 13.9 & $*$ \\
\hline \multirow[t]{2}{*}{$(\operatorname{lncR} I L)$} & B & 12.7 & 13.4 & 0.7 & 6.91 & 16.3 & $*$ \\
\hline & C & 12.3 & 13.6 & 1.3 & 12.1 & 12.4 & $*$ \\
\hline $\mathrm{MBH} 2$ & A & 18.3 & 20.5 & 2.2 & 12.2 & 3.7 & $*$ \\
\hline \multirow[t]{2}{*}{ (MolR IL) } & B & 17.9 & 19.8 & 1.9 & 11.1 & 2.9 & $*$ \\
\hline & C & 17.7 & 20.2 & 2.5 & 14.1 & 3.9 & $*$ \\
\hline $\mathrm{DAH}$ & A & 7.5 & 8.2 & 0.7 & 8.9 & 10.6 & $*$ \\
\hline \multirow[t]{2}{*}{ (MolR ML) } & B & 7.3 & 7.9 & 0.6 & 8.8 & 14.4 & n.s. \\
\hline & C & 7.7 & 8.7 & 1 & 12.6 & 8.4 & $*$ \\
\hline ANH & A & 2.9 & 3.4 & 0.5 & 17.2 & 18.2 & $*$ \\
\hline (IncR ML) & B & 2.9 & 3.4 & 0.5 & 17.2 & 26.9 & $*$ \\
\hline
\end{tabular}


Table I: Absolute intra-group differences between TI (week 14) and T2 (week 26) together with mean relative difference for each of the variables in each group evaluated. (Continued)

\begin{tabular}{|c|c|c|c|c|c|c|c|}
\hline & $\mathrm{C}$ & 2.6 & 2.9 & 0.3 & 11.5 & 35.3 & $*$ \\
\hline \multicolumn{8}{|c|}{ Transverse (mm) } \\
\hline GD & $A$ & 28.1 & 29.6 & 1.5 & 5.5 & 2.8 & $*$ \\
\hline \multirow[t]{2}{*}{ (GoR-GoL) } & B & 29.0 & 30.1 & 1.1 & 3.9 & 2.0 & * \\
\hline & C & 28.4 & 29.9 & 1.5 & 5.5 & 2.5 & * \\
\hline$C D$ & $A$ & 33.4 & 34.7 & 1.3 & 4.3 & 2.4 & $*$ \\
\hline \multirow[t]{2}{*}{$(\mathrm{CmR}-\mathrm{CmL})$} & B & 32.5 & 33.9 & 1.4 & 4.5 & 2.2 & $*$ \\
\hline & $\mathrm{C}$ & 33.2 & 34.4 & 1.2 & 3.7 & 1.3 & $*$ \\
\hline
\end{tabular}

$* P<0.05$

Angles (degrees)

Groups: A) placebo, B) IA etanercept, C) systemic etanercept. See figures 3, 4 and 5 for a description of the variables.

study at an earlier animal age was not possible due to Danish legislation on animal welfare. Systemic presensitization with antigen was initiated in age 10 weeks and the first IA TMJ antigen injections were introduced at age 14 weeks. In rabbits the greatest mandibular growth acceleration is seen in the early postnatal period and reduces at age 14 weeks [30], so obviously it would have been preferable to initiate this trial in younger animals. In this study, the significant inter-group differences in mandibular vertical growth occur within the final $10-15 \%$ of the overall mandibular growth. Therefore, we hypothesize that greater inter-group differences in several mandibular growth variables could have been revealed if the trial was

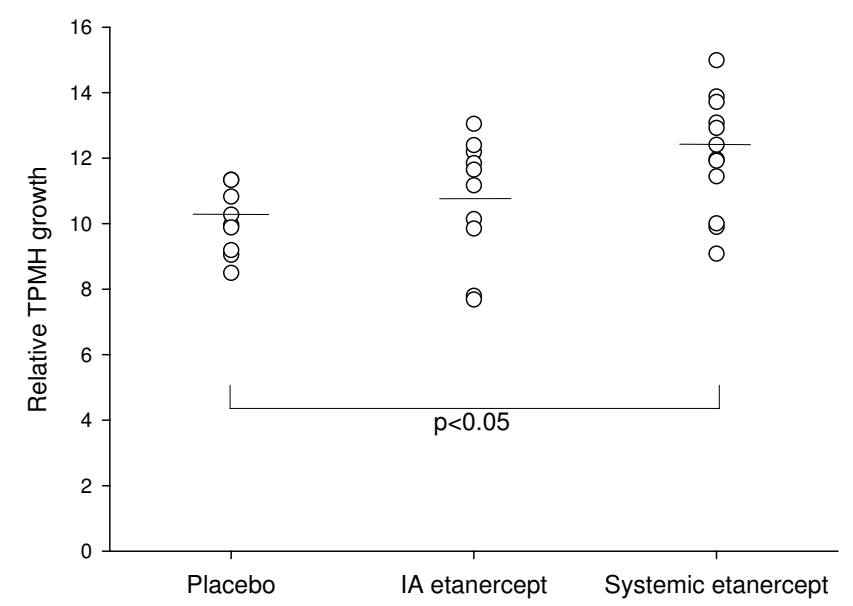

Figure 6

The relative growth of the total posterior mandibular height (TPMH). The growth of this variable was significantly larger $(p<0.05)$ in the systemic etanercept group (TPMH 12.6\% [Cl-95: II.0-I3.I]) compared with the IA saline group (TPMH I0.4\% [Cl-95: 9.2-II.5]). A non-significant trend $(p<0.1)$ towards a difference in the relative TPMH growth was observed between the systemic etanercept group (TPMH I2.6\% [Cl-95: I I.0-13.I]) and the IA etanercept group (TPMH 10.8\% [Cl-95: 9.2-12.2]). initiated in younger animals during the growth acceleration because of an increased mandibular growth potential left. This may explain the lack of differences on angular, sagittal and transverse measurements. Ten animals did not complete the full length of the study and it is questionable whether TMJ arthritis induction could have been initiated at an earlier animal age without extensive loss of animals. All animals lost in the experimental phase were lost due to anaphylactic shock right after the IA TMJ anti-

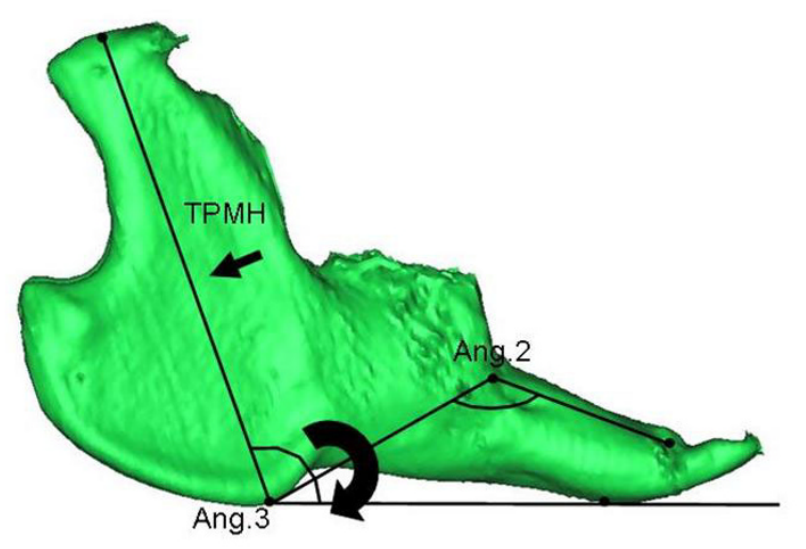

\section{Figure 7}

The findings of this study. Intervention with systemic etanercept monotherapy equivalent to the recommended human dose allows mandibular growth towards an original morphology by significantly improved growth of the total posterior mandibular height (see TPMH variable at small arrow). Systemic etanercept $(0.8 \mathrm{mg} / \mathrm{kg}$ weekly) administration is superior to IA TMJ etanercept administration at times of inflammatory flares in maintaining mandibular vertical growth. All three groups demonstrated an unfavourable clockwise posterior mandibular rotation pattern, illustrated by an opening of Angle 3 (large arrow). The most pronounced posterior mandibular rotation was observed in the IA saline group in which a closing of Angle 2 also occurred. 
gen injections. The majority of lost animals died during the first two antigen challenge procedures.

The orthopaedic treatment of JIA patients with TMJ inflammation is long of duration, comprehensive and requires good patient cooperation. Often the clinical signs of TMJ arthritis are vague and the disorder is often overlooked [6]. Early aggressive intervention against TMJ involvement aimed against the inflammatory process per se could allow mandibular growth towards an original morphology. Symptomatic and functional improvements of IA corticosteroid injections for the treatment of TMJ arthritis in children have been described $[9,11]$. However, previously we have published data supporting that, despite of significant inflammatory reduction, these injections have a highly unfavourable effect on the mandibular growth in experimental studies [12,13]. Therefore, searches for alternative local anti-inflammatory treatments are warranted in the future. This study suggests that early intervention with systemic etanercept monotherapy weekly is beneficial and allows growth towards an original morphology. It could be of great clinical interest to consider the effect of systemic etanercept as a compliment to an orthopaedic mandibular correction with orthodontic splint therapy in the intervention against early mandibular growth alteration in JIA patients. Another interesting clinical aspect is if a synergistic effect on mandibular growth can be achieved with a combination of methotrexate and systemic anti-TNF- $\alpha$ administration. Data have documented that monotherapy with methotrexate reduces TMJ destruction and growth alterations and craniofacial dysmorphology in polyarticular JIA children with TMJ arthritis [31]. In RA patients a synergistic good therapeutic effect on structural joint damage has been described when methotrexate and systemic anti-TNF- $\alpha$ therapy have been combined [32].

\section{Conclusion}

Treatment of experimental TMJ arthritis with systemic etanercept monotherapy weekly, equivalent to the recommended human dose, allows mandibular growth towards an original morphology which is unlike our previous findings with IA corticosteroids for the treatment of experimental TMJ arthritis. Weekly systemic etanercept administrations are superior to IA TMJ etanercept administration, at times of antigen induced inflammatory flares, in maintaining mandibular vertical growth.

\section{Abbreviations}

JIA: Juvenile Idiopathic Arthritis; TMJ: Temporomandibular Joint; IA: Intra-articular; TNF: Tumor Necrosis Factor; CT-scan: Computerized Tomography scans; RA: Rheumatoid Arthritis.

\section{Competing interests}

The authors declare that they have no competing interests.

\section{Authors' contributions}

PS, KDK, AK, TKP and TH designed and conducted the experiment and decided upon the context of the growth analysis. JG was responsible for CT-scan sessions and other aspects of these sessions. PS conducted all the measurements on the CT-scans and was responsible for the statistical analysis. PS drafted the initial manuscript. All authors have made significant contribution to the manuscript regarding content, interpretation and read and approved the final manuscript.

\section{Acknowledgements}

The authors would like to thank the financial supporters; The Research Foundation of Aarhus University, the Danish Council for Strategic Research and the Danish Medical Research Council. Furthermore, the authors would like to thank Paolo M Cattaneo for his technical assistance in relation to the CT-scans.

\section{References}

I. Bjork A: The use of metallic implants in the study of facial growth in children: method and application. Am J Phys Anthropol 1968, 29:243-54.

2. Enlow DH, Hans MG, editors: Growth of the mandible. In Essential of facial growth Philadelphia: Saunders; 1996:57-78.

3. Kjellberg H: Juvenile chronic arthritis. Dentofacial morphology, growth, mandibular function and orthodontic treatment. Swed Dent J Suppl 1995, 109:1-56.

4. Stabrun AE, Larheim TA, Rosler M, Haanaes HR: Impaired mandibular function and its possible effect on mandibular growth in juvenile rheumatoid arthritis. Eur J Orthod 1987, 9:43-50.

5. Stabrun AE: Impaired mandibular growth and micrognathic development in children with juvenile rheumatoid arthritis. A longitudinal study of lateral cephalographs. Eur J Orthod 1991, I3:423-34.

6. Pedersen TK, Kuseler A, Gelineck J, Herlin T: A prospective study of magnetic resonance and radiographic imaging in relation to symptoms and clinical findings of the temporomandibular joint in children with juvenile idiopathic arthritis. J Rheumatol 2008, 35:1668-75.

7. Pedersen TK, Gronhoj J, Melsen B, Herlin T: Condylar condition and mandibular growth during early functional treatment of children with juvenile chronic arthritis. Eur J Ortho 1995, I 7:385-94.

8. Pedersen TK: Clinical aspects of orthodontic treatment for children with juvenile chronic arthritis. Acta Odontol Scand 1998, 56:366-68.

9. Arabshahi B, Dewitt EM, Cahill AM, Kaye RD, Baskin KM, Towbin RB Cron RQ: Utility of corticosteroid injections for temporomandibular arthritis in children with juvenile idiopathic arthritis. Arthritis Rheum 2005, 52:3536-69.

10. Weiss PF, Arabshahi B, Johnson A, Bilaniuk LT, Zarnow D, Cahill AM, Feudtner $C$, Cron RQ: High prevalence of temporomandibular joint arthritis at disease onset in children with juvenile idiopathic arthritis, as detected by magnetic resonance imaging but not by ultrasound. Arthritis Rheum 2008, 58: I | 89-96.

II. Ringold S, Torgerson TR, Egbert MA, Wallace CA: Intraarticular Corticosteroid Injections of the Temporomandibular Joint in Juvenile Idiopathic Arthritis. J Rheumatol 2008, 35: I I57-64.

12. Kristensen KD, Stoustrup P, Küseler A, Pedersen TK, Nyengaard JR, Hauge EM, Herlin T: Quantitative histological changes of repeated antigen-induced arthritis in the temporomandibular joints of rabbits treated with intra-articular corticosteroid. J Oral Pathol Med 2008, 37:437-44.

13. Stoustrup P, Kristensen KD, Küseler A, Gelineck J, Cattaneo PM, Pedersen TK, Herlin T: Reduced mandibular growth in experimen- 
tal arthritis in the temporomandibular joint treated with intra-articular corticosteroid. Eur J Orthod 2008, 30: I II-9.

14. Kutukculer N, Caglayan S, Aydogdu F: Study of pro-inflammatory (TNF-alpha, IL-Ialpha, IL-6) and T-cell-derived (IL-2, IL-4) cytokines in plasma and synovial fluid of patients with juvenile chronic arthritis: correlations with clinical and laboratory parameters. Clin Rheumatol 1998, 17:288-292.

15. Macrae VE, Farquharson C, Ahmed SF: The pathophysiology of the growth plate in juvenile idiopathic arthritis. Rheumatology 2005, 45: II-19.

16. Aizawa T, Kon T, Einhorn TA, Gerstenfeld LC: Induction of apoptosis in chondrocytes by tumor necrosis factor-alpha. $j$ Orthop Res 200I, 19:785-96.

17. Martensson K, Chrysis D, Savendahl L: Interleukin-Ibeta and TNF-alpha act in synergy to inhibit longitudinal growth in fetal rat metatarsal bones. $j$ Bone Miner Res 2004, 19:1805-12.

18. Alstergren P, Kopp S: Insufficient endogenous control of tumor necrosis factor-alpha contributes to temporomandibular joint pain and tissue destruction in rheumatoid arthritis. J Rheumatol 2006, 33:1734-9.

19. Nordahl S, Alstergren P, Kopp S: Tumor necrosis factor-alpha in synovial fluid and plasma from patients with chronic connective tissue disease and its relation to temporomandibular joint pain. J Oral Maxillofac Surg 2000, 58:525-30.

20. Lovell DJ, Reiff A, llowite NT, Wallace CA, Chon Y, Lin SL, Baumgartner SW, Giannini EH, Pediatric Rheumatology Collaborative Study Group: Safety and efficacy of up to eight years of continuous etanercept therapy in patients with juvenile rheumatoid arthritis. Arthritis Rheum 2008, 25: I 496-I504.

21. Bliddal H, Terslev L, Qvistgaard E, Recke P, Holm CC, DanneskioldSamsoe B, Savnik A, Torp-Pedersen S: Safety of intra-articular injection of etanercept in small-joint arthritis: an uncontrolled, pilot-study with independent imaging assessment. Joint Bone Spine 2006, 73:7I 4-7.

22. Bliddal H, Terslev L, Qvistgaard E, Konig M, Holm CC, Rogind H, Boesen M, Danneskiold-Samsøe B, Torp-Pedersen S: A randomized, controlled study of a single intra-articular injection of etanercept or glucocorticosteroids in patients with rheumatoid arthritis. Scand J Rheumatol 2006, 35:34I-5.

23. Kristensen KD, Stoustrup P, Kuseler A, Pedersen TK, Nyengaard JR, Hauge $E$, Herlin T: Intra-articular vs. systemic administration of etanercept in antigen-induced arthritis in the temporomandibular joint. Part I: histological effects. Ped Rheu 2009, 7:5.

24. Bjork A, Skieller V: Growth of the maxilla in three dimensions as revealed radiographically by the implant method. $\mathrm{Br} J$ Orthod 1977, 4:53-64.

25. Yim DS, Zhou H, Buckwalter M, Nestorov I, Peck CC, Lee H: Population pharmacokinetic analysis and simulation of the timeconcentration profile of etanercept in pediatric patients with juvenile rheumatoid arthritis. I Clin Pharmacol 2005, 45:246-56.

26. Alstergren P, Larsson PT, Kopp S: Successful treatment with multiple intra-articular injections of infliximab in a patient with psoriatic arthritis. Scand J Rheumatol 2008, 37:155-7.

27. Bang S, Enlow DH: Postnatal growth of the rabbit mandible. Arch Oral Biol 1967, 12:993-8.

28. Kapila S, Lee C, Tavakkoli Jou MR, Miller AJ, Richards DW: Development and histologic characterizations of an animal model of antigen-induced arthritis of the juvenile rabbit temporomandibular joint. J Dent Res 1995, 74:1870-79.

29. Tavakkoli-Jou M, Miller AJ, Kapila S: Mandibulofacial adaptations in a juvenile animal model of temporomandibular joint arthritis. J Dent Res 1999, 78: | 426-1435.

30. Masoud I, Shapiro F, Moses A: Longitudinal roentgencephalometric study of the growth of the New Zealand white rabbit: cumulative and biweekly incremental growth rates for skull and mandible. J Craniofac Genet Dev Biol 1986, 6:259-287.

31. Ince DO, Ince A, Moore TL: Effect of methotrexate on the temporomandibular joint and facial morphology in juvenile rheumatoid arthritis patients. Am J Orthod Dentofacial Orthop 2000, I I 8:75-83.

32. Klareskog L, Heijde D van der, de Jager JP, Gough A, Kalden J, Malaise M, Martín Mola E, Pavelka K, Sany J, Settas L, Wajdula J, Pedersen R, Fatenejad S, Sanda M, TEMPO (Trial of Etanercept and Methotrexate with Radiographic Patient Outcomes) study investigators: Therapeutic effect of the combination of etanercept and meth- otrexate compared with each treatment alone in patients with rheumatoid arthritis: double-blind randomised controlled trial. Lancet 2004, 363:675-8I.
Publish with BioMed Central and every scientist can read your work free of charge

"BioMed Central will be the most significant development for disseminating the results of biomedical research in our lifetime. "

Sir Paul Nurse, Cancer Research UK

Your research papers will be:

- available free of charge to the entire biomedical community

- peer reviewed and published immediately upon acceptance

- cited in PubMed and archived on PubMed Central

- yours - you keep the copyright

Submit your manuscript here:

http://www.biomedcentral.com/info/publishing_adv.asp 